\title{
König Joram von Juda und der Text von 2 Kön 8, 2I-24.
}

Das Problematische der meisten Correcturen am masoretischen Texte einzuschärfen, sind wenige Stellen so geeignet wie 2 Kön 8, 2I-24. Zwar dass im jetzigen Wortlaut v. 2I so ziemlich das Gegentheil dessen besagt, was die Stelle ursprünglich gemeldet haben wird, ist wohl ziemlich anerkannt. Aber nicht nur bleibt zweifelhaft, was der ursprüngliche Wortlaut war, sondern es ist vor allem nicht auszumachen, wer den ursprünglichen Sinn in sein. Gegentheil verkehrt hat. Und danach richtet sich dann weiter das Urtheil über die Ursprünglichkeit von v. 24 und über die Glaubwürdigkeit seiner Angaben.

In der Geschichte des Volkes Israel I, 537 A I hatte ich als ursprünglichen Wortlaut angenommen ,und es zog Joram mit all seinen Wagen hinüber nach Sa'ir (So'ar?), da machte sich Edom Nachts auf und umstellte ihn, und es floh das Volk zu seinen Zelten". Im Texte nahm ich, ohne alle Consequenzen aus dieser Vermuthung zu ziehn, an, es sei Joram mit seinen Wagenkämpfern umstellt .worden, habe sich aber durchschlagen können. Diese Auffassung hat zur Voraussetzung, dass man entweder annimmt, הסביב sei unmittelbar nebeneinander in völlig gleicher Bedeutung

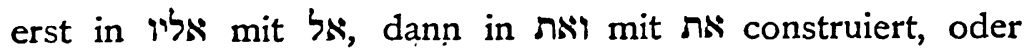
dass man את מליץ fü emendiert. Das erstere nehmen LXX

Zeitschrift f. d. alttest. Wiss. Jahrg. 2x. II. Igor. 


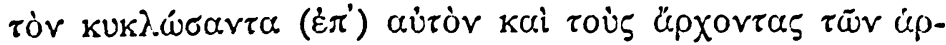

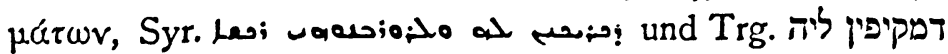
an. Es ist jedoch kein Grund einzusehn, der eine solche beispiellose Doppelconstruction veranlasst haben könnte. Aber auch אתו für zu emendieren empfiehlt sich nicht, da kein Grund ersichtlich ist, der die Verschreibung eines ursprünglichen את אליו va veranlasst haben könnte. Durch das folgende ואת musste ursprüngliches geradezu in seinem Bestande geschützt werden.

Hat man aber אלין festzuhalten, so ist der Text zweifellos verdorben, da sich ואליו מואת nicht anschliesst, und da weiter nicht gesagt wird, was die שרי הרכב im Unterschied הסביב העם הon auf diesem Kriegszuge betraf. Ferner ist schon durch die scriptio plena verdächtig. Hat man הליב festzuhalten, so ist bei der Correctur des Verses davon auszugehn, dass סבב אל in solchen Zusammenhängen sich jmdm zuwenden, zukehren, nämlich um ihn anzufallen, jmdn durch eine Kehre anfallen, angreifen bedeutet, vgl. ויפבו 2 עליו להלחם 2 Ch I8, 3I, wonach vielleicht - jedoch nicht sicher cf. 2 Sa 6, IO - ויפרו עליו להלחם I Kö 22, 32 zu emendieren

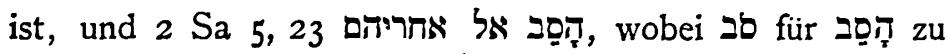
lesen ist. (Das $\pi$ erklärt sich aus Dittographie. Es geht תעלה הסביב אליו Ist dies richtig, so gehous). Ist das, was dafür ursprünglich im Texte stand, nicht hinter

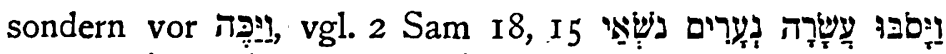

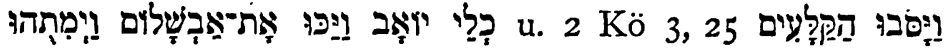

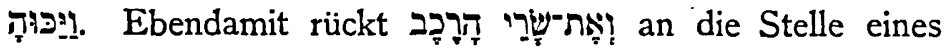
Objectes von אדום Subject des während Weiter zwingt ואת zu der Annahme, dass vorher ein anderes Object von nur der König Joram in Betracht kommen. Er steckt in

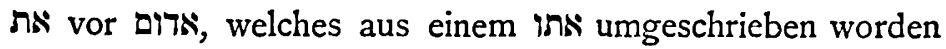
sein wird. Nun erst tritt der Schlusssatz 
in logische Beziehung zu dem Vorhergehenden. Die Masse des Heeres theilt das Schicksal der Führer nicht. Das Heer fährt auseinander. Der gemeine Mann rettet sich in seine וייפה את אדום nachat. Dagegen ist וינם העם לאהליו ganz unbegreiflich. Sind sonach auch meine Ausführungen in der Geschichte des Volkes Israel der Verbesserung bedürftig, so bestätigt doch diese neue Untersuchung des Textes der Stelle, dass ich in der citierten Anmerkung zur Geschichte des Volkes Israel I, 537 mit RechtEdom als Subject von ק viur absichtliche Correctur angesehn habe.

Haben wir nach dem soeben Ausgeführten anzunehmen, dass v. 2 I im ursprüglichen Wortlaute gelautet hat: ויעבר

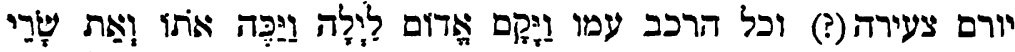

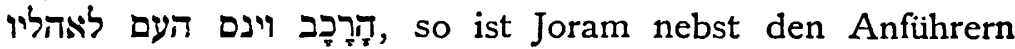
seiner Wagen im Kampfe mit den aufständischen Edomitern gefallen, und es erklärt sich hieraus, dass er nach v. I 7 nur 8 Jahre regiert hat. Dieser Annahme widerspricht freilich v. וישכב יורם עם אבתיו ויקבר בעיר דוד 24 , mindestens sind die vier ersten Worte des Verses damit nicht in Einklang zu bringen. Die vorgeschlagene Emendation von v. 2 I zieht sonach eine weitere von v. 24 nach sich.

Ist nun auch ziemlich sicher, dass der Bericht über Jorams Edomiterkämpfe v. 2 I nur in entstelltem Zustande auf uns gekommen ist und ursprünglich wie angenommen gelautet hat, so ist doch durch diesen Nachweis das Recht einer Emendation des Wortlantes des Königsbuches noch nicht sicher gestellt. Denn man muss mit der Möglichkeit rechnen, dass schon der Epitomator und nicht erst ein späterer Redactor oder Überlieferer das Bedürfnis empfunden hat, die unliebsame Thatsache aus der Welt zu schaffen, dass Joram von Juda im Kampfe mit den Edomitern in wenig rühmlicher Weise seinen Untergang gefunden hat, und dass schon der Epitomator in bewusster Weise den ursprünglichen 
Wortlaut von v. 2 I in sein Gegentheil verkehrt hat. Dann entfällt zunächst jedes Recht, an v. 24 etwas zu ändern. Aber es wird auch damit der jetzige Wortlaut von v. 2 I gehalten, denn wir haben v. 2 I nur als Bestandtheil der Epitome. Nur den von dieser gebotenen Wortlaut haben wir zu geben, eventuell wiederherzustellen. Nur wenn wir annehmen dürfen, dass der Epitomator den ursprünglichen Wortlaut der Nachricht geboten hat, haben wir in v. 2I und danach in v. $24 \mathrm{zu}$ ändern. Denn nur dann müssen wir den jetzigenWortlaut vonv.24von einer späteren Handherleiten. Da wir diese Annahme aber nicht erweisen können, so werden wir uns an besten hier wie an andern Stellen des Alten Testamentes mit einer Vermuthung darüber begnügen, was der ursprüngliche Wortlaut war, und wir werden uns freuen . dürfen, dass dieser Vermuthung ein besonders hoher Grad von Wahrscheinlichkeit eignet. Damit aber komme ich zu dem Punkte, der bei der ganzen Frage am meisten inter essiert.

- Der Chronist hat 2 Kö 8, 2I augenscheinlich schon in seinem jetzigen Wortlaute vorgefunden. Im hebräischen Texte von $2 \mathrm{Chr}$ 2I, 9 fehlt jetzt der Schlusssatz İ העצם לָאהָהָליי Vorgefallenen verwischt worden. Es ist jedoch sehr fraglich, ob der Satz schon vom Chronisten gestrichen worden ist, da LXX ihn bietet.

B. Stade. 